\title{
Periferias culturales: aproximación introductoria al etnocentrismo
}

\author{
"Mi hijo ¿Qué vas a ser en la vida? \\ ¡Mamá quiero ser etnocentrista! ...” \\ Philippe Schaffhauser ${ }^{1}$
}

\begin{abstract}
Con tal de desterrar todo tipo de ambigüedad respecto del tema que voy a tocar hoy, quiero advertir que el etnocentrismo es, ante todo, una mirada cultural que enfoca al otro en tanto ajeno, lejano y exótico. Cada mirada cultural peca por etnocentrista, aun cuando haya de una sociedad a otra varios grados de etnocentrismo. En cada mirada cultural, se mide la distancia que separa lo ajeno de lo propio. $Y$ finalmente, cada mirada cultural tiene además de una carga ética, una dimensión estética. Además, debo decir que asumo totalmente el sesgo filósofoantropológico del conjunto de reflexiones que presento en este espacio de discusión e intercambio académicos. Sin embargo, cabe mencionar que en la segunda parte de este artículo procuro cuando menos establecer une serie de conexiones con lo que caracteriza la situación actual del indigenismo en México, a través de la desaparición del INI y su reemplazo burocrático y sexenal por la CDI. Asimismo, quiero enfatizar lo siguiente: $\mathrm{mi}$ postura consiste en criticar el etnocentrismo en general y traer a colación algunos elementos que ponen de manifiesto los retos indigenistas actuales que orientan políticas y programas
\end{abstract}

del estado mexicano hacia grupos culturales como las comunidades indígenas de ese país, a sabiendas de que dicha postura es, a su vez, etnocentrista. Finalmente, el artículo que aquí presento debe entenderse como un acercamiento al problema del etnocentrismo $y$ no en tanto fruto de una investigación puntual dedicada a un aspecto de ese tema y cuyos resultados podría presentar y comentar cabalmente.

Para situar mejor mi intención rectora, diría que mi esfuerzo teórico y metodológico apunta más bien a tomar en serio esa parte de etnocentrismo que a todos nos incentiva a tocar tal o cual frente cultural de la humanidad para volverlo problema antropológico. De alguna manera, ma démarche suena a re-habilitar el etnocentrismo para afirmar con toda claridad que el reconocerse etnocentrista es el único medio, cuando se es antropólogo, de producir una crítica realista (mas no ideológica) del etnocentrismo. Con ello no invento nada, sino que a mi manera sigo el camino trazado por Clifford Geertz, que acaba de despedirse de este mundo dejándonos por un tiempo solos frente a los problemas del relativismo

\footnotetext{
${ }^{1}$ Sociólogo, Universidad de Perpiñan, Francia
} 
cultural sobre los cuales el atento lector de Wittgenstein y Ryle reflexionó con harta profundidad a lo largo de su vida académica. De Geertz heredamos el etnocentrismo cultural bajo el siguiente problema antropológico: el yo-testigo, el yo-escritor y el yo-intérprete conforman las tres facetas del sujeto cultural que no dejamos de ser los antropólogos todos, tanto aquí como allá. El texto antropológico que cuenta sobre otras culturas no es más que el encuentro entre un relato (significa entonces que el texto de antropología está a medio camino entre historia, mito y finalmente ficción) y un discurso cuya característica primera es remitir a un contexto mediante la identificación de indicios políticos, sociales y culturales que constituyen el mundo del que escribe, del que describe, del que observa; esto es el mundo del antropólogo.

En la cosmogonía mexica, el centro en tanto sitio físico significaba el meollo del desorden, el lugar del desasosiego en el cual la sociedad tenochca sufría a veces embates y torbellinos. Entre las filas de los mexicas, el centro propiciaba temor y pavor. Resulta curioso pensar que hoy día el concepto de centro es el parangón del orden social, el símbolo de la estabilidad político-estatal y económica². Es aun más curioso imaginar que el centro pudiera ser el sitio desde donde mirar al otro en tanto ser cultural. Luego, se torna entonces apremiante examinar de cerca lo que acarrea un concepto ${ }^{3}$ como etnocentrismo.

En primer lugar, podemos anotar que el etnocentrismo se fundamenta en una división entre centro y periferia de modo que bien podemos deducir de este par de oposiciones otro más conformado por el etnocentrismo y el neologismo etnoperiferismo, lo cual, a decir del linguista Román Jakobson, no suena muy poético ${ }^{4}$ pues carece de la rítmica que, a través de la estética, Ilega a embrujarnos a veces. Luego, es imprescindible entonces señalar que la palabra etnocentrismo y las instrucciones simbólico-lingüísticas para su cabal empleo pertenecen a un sistema de pensamiento harto dualista. De claro en claro, dicho sistema representa la vertiente cognitiva de formas culturales occidentales, es decir, europeas y judeo-cristianas y las que han surgido de ellas.

En segundo lugar (sic), podemos agregar que pensar es un acto espacial y desde luego es algo especial. En efecto, pensar requiere primero el ubicarse ${ }^{5}$. Discrepando con el famoso aforismo cartesiano "Je pense donc je suis", se trataría de plantear que "se es, siempre y cuando haya ubicación"6. El problema se torna tal vez más candente cuando se trata de hablar a nombre de una cultura para tipificar las diferencias con respecto a las demás culturas. Este acto consiste en trazar los límites entre un adentro y un afuera. La ubicación sería una suerte de acto fundador, pues a partir de ella se divide el mundo en dos partes: lo central y lo periférico. Vale la pena continuar este peritaje para darse cuenta pronto de que estamos frente a un problema de lenguaje, es decir, de un juego de Ienguaje. Conforme al abanico conceptual de la ciencia lingüística, la palabra etnocentrismo es un sintagma. Acabamos de ver escuetamente con la forma centrismo su primer componente que

\footnotetext{
${ }^{1}$ Hago un évidente guiño (i.e. el famoso " guiño ryleano ») al ensayo de Geertz Ici et là-bas, l'anthropologue comme auteur, Paris, Métailié, 1996.

2 Pónganse a pensar cavilosamente : ¿Dónde exactamente puede ubicarse el mercado del que nos comentan los economistas neoliberales? Todos ellos coinciden en decir que éste tiene que encontrarse forzosamente en el centro ... Luego entonces hablar de "mercado" es remachar la idea de "centro".

3 Es preciso aclarar que el uso que hago aquí del predicado "concepto" para calificar el vocablo etnocentrismo sirve para trazar una frontera ética que separa la antropología en tanto actividad de conocimiento de la antropología en tanto actividad política. Dicho de otro modo, la palabra etnocentrismo describe idealmente lo que el antropólogo debe rechazar: la superioridad moral del uno sobre el otro. Por ello, el etnocentrismo no forma parte del lenguaje antropológico hoy día. En cambio, sirve para delimitar a éste.

${ }^{4}$ Cf. Roman J akobson in Huit questions de poétique, Paris, Seuil, 1977.

${ }^{5}$ Es también curioso darse cuenta, por ejemplo, que Francia siempre se sitúa en el centro en los mapas que utilizan los maestros de las escuelas primarias de ese país. La anécdota podría parecer irrelevante por reflejar una obviedad (tal vez sea el caso en muchos otros países), pero si tomamos en cuenta tanto el pasado colonialista de Francia como el número de migrantes oriundos de las antiguas colonias africanas principalmente y cuyos hijos asisten a las escuelas francesas de hoy día, el dato deja de ser nimio por completo.

${ }^{6}$ Plantear de esta manera el problema identitario conduce a una suerte de pensamiento relativista, puesto que bajo este enfoque uno se conformaría de acuerdo a un contexto sociocultural determinado y, por ende, esto desemboca en una negación del "ser" en tanto categoría universal. Asumo en parte la crítica que me podría estar dirigida, pero debo aunar que el universalismo es también una construcción histórica que corresponde a un espacio determinado: el occidente.
} 
remite al campo de la geografía. El prefijo etno remite al lato vocabulario de la cultura. Significa en griego "pueblo", Io cual implica la existencia de un territorio en que éste viva. Cabe recordar que, muy a menudo, el nombre del pueblo deriva del topónimo ${ }^{7}$. Asimismo, el examen de ese prefij o supone que la categoría del etno sea totalmente descriptible; es decir, que uno o varios investigadores serían capaces de deslindar lo que es de lo que no es, como si la cultura fuera un ser de carne y huesos étnicos y por tanto cupiera en un espacio determinado.

Lo anterior manifiesta una clase de problema para que cualquiera opine a partir de lo que considera su cultura, desde las bases sólidas que la hacen erguir y que ponen en alto sus símbolos como son la lengua, el arte, la religión, la educación, el trabajo, el juego, la guerra, la sexualidad, la actitud ante la muerte, etc ... Si admitimos la idea de que juzgar y sentenciar al otro tiene algún sentido (lo cual cobra la forma de un espinoso asunto que puede reducirse a una nimia polémica en torno al enfoque relativista), entonces debería uno sustentar su reflexión en un conocimiento muy a fondo de lo suyo, es decir, los patrones culturales que les son cercanos y familiares. Un conocimiento tal rara vez se logra por más culto que sea el individuo que pretende juzgar al otro. Otro tipo de problema también importante remite a la distancia que existe entre el juez cultural que dictamina la conducta social del otro y la cultura en la cual se encuentra éste ${ }^{8}$ : ¿Cuán lejos se sitúa un sistema cultural respecto de otro? Contestar esta pregunta nos conduce a indagar el sistema simbólico a partir del cual se construye el juicio etnocentrista, es decir ¿cómo se representa al otro una cultura determinada?

Finalmente, el examen del prefij o etno pone al descubierto otra clase de problema: con el etnocentrismo, la dificultad no parece tener mucho que ver con dicho prefijo sino que atañe probablemente al radical "centro". A guisa de juego podemos sustituir el prefijo etno por otro y obtener otros sintagmas tales como: sociocentrismo, cronocentrismo, semiocentrismo, alocentrismo, sexocentrismo, plutocentrismo, ludocentrismo, geocentrismo, etc. Dicho de otro modo, cualquier forma de centrismo es la expresión de un sistema de creencias que no sólo permite a los individuos pensar, opinar, sentir, elegir, encubrir, expresar, reflexionar, cavilar, aclarar, enseñar sino sobre todo favorece de modo cardinal la acción individual y/ o grupal. Más adelante, volveré a tocar este punto de discusión.

De acuerdo a la enciclopedia electrónica Hachette multimedia, 2001 Yahoo! France $^{9}$, existen tres acepciones para la palabra etnocentrismo:

- Primero: significa negar simple y sencillamente una sociedad, su cultura y los miembros de la misma ;

- Segundo: remite a la aculturación, que consiste en obligar a un grupo a adoptar valores y prácticas culturales aj enas, es decir del grupo considerado el parangón civilizatorio ; y

- Finalmente: significa dictaminar una sociedad y la cultura correspondiente de acuerdo a criterios propios de la sociedad que sirve de modelo, lo cual conduce a negar toda especificidad y diversidad socioculturales.

Vale la pena detenerse un poco para comentar estas definiciones que enfocan problemas distintos. Para ello quizá es necesario acudir a algunos hechos históricos muy sonados.

1) En la primera acepción todo parece indicar que detrás de ésta se encuentra el nihilismo nazi para con los judíos. El nazismo achacaba a los judíos ni más ni menos que el derecho fundamental de existir. La destrucción de lo aj eno para enaltecer lo propio era el programa político del tercer Reich. Se trataría tal vez de un caso extremo de etnocentrismo puesto que conduce a aniquilar al otro. A éste lo llamaría

\footnotetext{
${ }^{8}$ Al respecto, el filósofo francés Maurice Blondel escribe hacia fines del siglo XIX: « La sévérité de nos jugements sur les autres tient d’ordinaire à ce que nous prenons notre idéal pour notre pratique et leur pratique pour leur idéal. » M. Blondel, L'Action, p. 169

${ }^{9}$ Cf. fr.enciclopedia.yahoo.com

${ }^{10} \mathrm{Cf}$. J ean-Paul Sartre Réflexions sur la question juive, Paris, Gallimard, collection Folio/ Essais, 1990.
} 
etnocentrismo etnocidiario y 0 altericidio ${ }^{10}$.

2) En el segundo sentido, nos enfrentamos a la forma etnocéntrica más común, pues remite a todos los proyectos coloniales implementados por los llamados países occidentales, a lo largo del siglo XIX. Entre ellos encontramos a la Francia decimonónica, cuyo papel en África era entonces civilizar a los salvaj es, obsequiarles las luces filosóficas y revolucionarias. A este etnocentrismo le pondré el nombre de etnocentrismo civilizatorio y/o pragmático ${ }^{11}$.

3) $Y$ finalmente, en el último sentido se trata de un problema ético-moral, pues la sociedad que sirve de modelo quiere imponer sus valores volviéndolos universales en vez de considerarlos un punto de vista cultural entre muchos otros. A este etnocentrismo lo llamaría etnocentrismo ideológico y/o dogmático, puesto que da la pauta para cualquier forma de ingerencia en nombre de un supuesto orden ético internacional. No hay que ir muy lejos para buscar situaciones que ejemplifiquen dicha concepción hoy día: la segunda Guerra del Golfo basta ampliamente.

Sin embargo, podemos discrepar contra esta última versión: si bien el etnocentrismo es un juicio muy sesgado hacia las demás culturas, hay que recalcar el carácter harto universal del etnocentrismo que encontramos en el juicio de cada sociedad hacia sus vecinos culturales y después es preciso recalcar que el juicio etnocéntrico estriba en la diversidad cultural, pues sin ella se esfumaría en tanto weltanschuung (visión del mundo). Por ello, esta clase de etnocentrismo no tiende a negar al otro, sino consiste más bien en jerarquizarlo. No se trata de pasar por alto las otras culturas sino que es cuestión de ordenar su grado de desarrollo. Supone, asimismo, confundir y tal vez revolver completamente juicios de valores y juicios empíricos ${ }^{12}$. Según este enfoque, el etnocentrismo que corresponde a esta tercera acepción sería una forma de pensar irredéntica, nacionalista y seguramente chauvinista. El etnocentrismo de la segunda definición en cambio, sería imperialista, es decir, hoy día neo-libreal y pro mundialista. Ahora bien, centremos el debate en el medio académico especialmente en el que conforman la antropología y la sociología.

Parece oportuno indagar el origen histórico del concepto de etnocentrismo y, para empezar, investigar quién fue el científico social que acuñó dicho vocablo. Vale la pena decir que es curioso notar que dicho concepto haya cobrado tanta importancia y cundiera por gran parte de la literatura antropológica para obviamente ser criticado y desechado del lenguaje afín a la práctica de campo, de tal suerte que, para bien y para mal, su autor quedara casi en el olvido. Se trata de una paradoja. William Graham Sumner, nacido en 1840 y fallecido en 1910, es ese autor desconocido que inventara el neologismo etnocentrismo ${ }^{13}$. Era sociólogo e y estaba influido por las teorías evolucionistas de su coetáneo británico Herbert Spencer. W. G. Sumner era catedrático en la Universidad de Yale, lo cual significa que, para ese entonces, no era ningún desconocido. Se consideraba anarquista, puesto que el evolucionismo que pregonaba era crítico acérrimo de las teorías creacionistas procedentes del ideario religioso en boga en los EE.UU. Dicha postura le trajo muchos enconos de parte de sus colegas de Yale. Por decirlo de alguna manera, en el marco de esta polémica, se enfrentaba la providencia versus la determinación, el orden divino contra el orden natural.

Sumner era de la idea que el mundo se conforma(ba) de varias culturas, todas ellas encaminadas hacia una sola historia dividida en distintas etapas evolutivas: del salvaj ismo a la civilización pasando por la barbarie ${ }^{14}$.

\footnotetext{
${ }^{11}$ Según esta ideología, en Africa la derrota de los nativos ante el poderío militar europeo era el signo de que el proyecto ya fuera inglés, francés, español, portugués y en su caso alemán era justo, es decir, verdadero. En los EE. UU., la exploración del Far West y los territorios indios a comienzos del siglo XIX (con W. Clark y M. Lewis) da la pauta más tarde al proyecto colonizador sustentado en la ideología del "Destino manifiesto".

12 Empero, L. Wittgenstein sostiene que todo juicio empírico deriva de un juicio de valor y F. Nietzsche pregona, por su parte, que no hay hechos, sólo hay interpretaciones.

13 Dicho término figura en el diccionario francés Larousse por vez primera hacia 1950, bajo la forma de su predicado etnocéntrico. Cf. J. Dubois et alii in Dictionnaire étymologique et historique du français, Paris, Larousse, 1997, p. 273.

14 Estas son las categorías que plantea Henri Lewis Morgan para explicar la diversidad cultural imperante en el mundo.
} 
Fue también uno de los pocos pioneros de la sociología norteamericana al igual que WEB DuBois, Lester Ward, Thorstein Veblen y la camada que iba a conformar destacadamente la llamada primera escuela de Chicago. Es el autor de un artículo titulado "sociology" , publicado en 1881 por la Universidad de Princeton y un tratado más o menos famoso sobre las costumbres y las normas sociales ${ }^{15}$. Ahora bien, hace falta precisar lo que Sumner concibe por etnocentrismo:

“[El etnocentrismo] Es el nombre técnico para la tendencia a considerar a su grupo el centro de todas las cosas, pues todos los demás son evaluados con respecto a ése. Se trata de una temprana alusión al grupo de referencia. [Sumner] Define "el patriotismo" como la lealtad con respecto al grupo cívico al cual pertenece uno por nacimiento u otro tipo de vínculo con el grupo, y el chauvinismo como la feroz y jactanciosa afirmación de sí mismo; a juicio de Sumner son expresiones diversas del mismo mecanismo de camaradería en el grupo de dentro y el grupo de fuera." 16

Hace un instante comentaba yo la suerte que sufrió la palabra etnocentrismo entre la comunidad de antropólogos, puesto que a través de la crítica de la misma arremetían contra sus colegas evolucionistas. Asimismo, dicho vocablo ha venido a conformar un punto fronterizo que separa la antropología de otras disciplinas sociales. Tocar el tema del etnocentrismo entre la comunidad de antropólogos significa plantear un problema de orden epistemológico y deontológico. La actividad antropológica no puede obviar el marco ético en el cual tiene que grabar sus logros y hallazgos cognitivos.

Otro fue el trato que recibió dicho concepto entre la comunidad de sociólogos. Así R. K. Merton acoge el término con beneplácito. Le es precioso para acuñar su teoría funcionalista de los grupos de referencia y grupos de pertenencia ${ }^{17}$. La discrepancia entre sociólogos y antropólogos ante el neologismo de Sumner no es un dato nimio, puesto que la sociología es una disciplina muy influida por la ciencia histórica y la antropología por la filosofía. Otra explicación tentativa es que tradicionalmente el objeto de la sociología ha sido lo propio (es decir, la cultura a la cual pertenece y en la cual participa el investigador sociólogo) a diferencia de la antropología, cuyo obj eto de estudio se centra en la universalidad de lo ajeno.

Otro elemento para entender mejor esta diferencia gira en torno al imperio de la problemática del cambio social en la ciencia sociológica. Las muchas interrogantes que despierta aquélla proceden en buena parte del paradigma evolucionista. Según este enfoque, toda sociedad está condenada a cambiar sus formas sociales y su organización social. Cuando se detiene el proceso de cambio social, significa que la sociedad está retrocediendo. La línea evolutiva parte de grupos homogéneos sencillos a sociedades heterogéneas complejas. Sumner era sociólogo-evolucionista y acuñó la palabra etnocentrismo. Luego entonces, asumo la idea de que existen vínculos de parentesco entre la sociología en tanto actividad empírica, el evolucionismo en tanto doctrina científica $y$, por así decirlo, el etnocentrismo en tanto reacción psicológica ante la presencia del otro.

Sea lo que fuere, a partir de esta diferencia epistomológica ${ }^{18}$ es interesante notar que si bien es cierto que a través del uso del concepto etnocentrismo se manifiesta un rechazo hacia quien pretende dictaminar moralmente el fondo cultural de otros pueblos, se debe aceptar a la par que dicha postura externaliza un punto de vista identitario. En otras palabras, con el problema del etnocentrismo volvemos a plantear el problema de la relación entre identidad y alteridad ${ }^{19}$. Pero algo nuevo se vislumbra en el espectro de esta

\footnotetext{
${ }^{15}$ Cf. W. G. Sumner, Folkways : a study of the sociological importance of usages, manners, customs, mores and morals, 1906.

16 Cf. Robert King Merton, Éléments de théories et de méthode sociologique, Paris, Armand Colin, 1997, p. 354

17 Ibidem.

18 Yo preferiría optar por la palabra "matiz" para dar cuenta mejor de esta situación interdisciplinaria.

19 Véase Ph. Schaffhauser "Indiens et identité au Mexique : I'exemple de la Meseta Purépecha”, Doctorado en sociología por la Universidad de Perpignan, 1997.
} 
problemática: primero es la identidad, luego la alteridad. No estamos frente a un dualismo más propio del pensamiento occidental que termina por difundirse a través del mundo. Se trata de una relación procesual: primero está la identidad y para que ella cobre existencia tiene que enfrentarse ${ }^{20}$ en otro momento con la alteridad. Significa que interesarse por el etnocentrismo no es poner énfasis en el juicio incipiente que expide una cultura hacia otra sino que esa suerte de fallo es el reflejo de una interioridad cultural, una forma de pensar y preconstruir al otro para actuar respecto de él. El pensamiento etnocéntrico es harto ideológico (o si se quiere, cultural) puesto que devela una postura émica, conforme a la jerga conceptual-antropológica del norteamericano Clifford Geertz ${ }^{21}$. De ahí se puede deducir una serie de hipótesis de trabajo:

- Significaría que, como lo había señalado Claude Lévi-Strauss ${ }^{22}$, cada cultura es etnocéntrica, pues ninguna sociedad puede pasar por alto su propia cosmogonía, soslayar sus propios prejuicios; dicho de otro modo, siempre lo desconocido se explica con base en lo conocido. Este conocimiento siempre tiene tinte cultural. No existe ningún punto de vista de $\operatorname{Dios}^{23}$.

- Significaría también que, gracias al etnocentrismo, esdecir atravésdel menosprecio - la sobrevaloración, el chauvinismo ${ }^{24}$ o el malinchismo (es decir, suerte de alocentrismo de cuño mexicano), la diversidad cultural sigue siendo tal ${ }^{25}$;

- Significaría que, detrás del etnocentrismo, actúa un sistema de creencias que predispone a los hombres a emprender tal o cual cosa hacia sus prójimos;

- Significaría que el etnocentrismo plantea un problema ético donde vienen a confundirse
Ios juicios de valores y los juicios empíricos; - Significaría que para completar el abanico de “capitales" teorizados por Pierre Bourdieu², el problema del etnocentrismo despierta una suerte de capital alteritario: existen varias formas de etnocentrismo que documentan no tanto lo que es la cultura del otro, sino lo que son las relaciones sociales en una sociedad determinada.

- Significaría finalmente que en vez de hablar de etnocentrismo valdría la pena hablar de sociocentrismo puesto que la postura interior que construye el etnocentrismo no es más que la expresión clasista que impera en una sociedad capitalista determinada.

La última propuesta merece ser analizada más a fondo. El pensamiento de W.G. Sumner adolece de autoreflexividad: vuelve natural su propio punto de vista etnocéntrico que es, ni más ni menos, el producto de una sociedad sumamente compleja como lo eran IOS EE.UU. de principios del siglo pasado. El sociólogo estadounidense no se da cuenta que su reflexión está totalmente inmersa en entreveradas relaciones sociales en las cuales el mismo participaba. Dicho de otro modo, no problematiza su propia postura social dentro de la jerarquía propia de la sociedad norteamericana de aquel entonces.

Sin embargo, si bien el etnocentrismo es una clase de opinión a priori, no todos los prejuicios sobre el otro son falsos. Algunos de ellos deben ser examinados acuciosamente para determinar su grado de verosimilitud. Aquí, lo que se discute no es tanto rescatar el etnocentrismo transformándolo en un concepto clave para enfocar y entender la relación entre el uno y el otro ${ }^{27}$, sino que se trata de investigar qué

\footnotetext{
20 En el estricto sentido fenomenológico de la relación con el otro.

${ }^{21}$ Cf. Clifford Geertz, Los usos de la diversidad, Barcelona, Paidós, 1999 y La interpretación de las culturas, Barcelona, Gedisa, 1989.

22 Cf. Le regard éloigné, Paris, Plon, 1983 y Race et histoire, Paris, Éditions Gonthier, Unesco, 1961.

${ }^{23}$ Cf. Hilary Putnam, Raison, vérité et histoire, Paris, Éditions de Minuit, 1984.

${ }^{24}$ Vale la pena detenerse en dicho vocablo para examinar su etimología. Deriva del apellido de un tal Chauvin, Nicolas infante de las tropas de Napoleón Bonaparte. A este personaje incipiente de la historia francesa se le consideraba primero símbolo de la valentía del soldado francés. Más tarde, el vocablo chauvinista vino a ser sinónimo de patriotismo exacerbado y finalmente de fanatismo nacionalista.

${ }^{26}$ Entre otros libros del heredero de Durkheim, Weber y Marx destacan al respecto: Le sens pratique, Paris, Minuit, 1980 \& Esquisse d'une théorie de la pratique, Paris, Minuit, 1980 \& Ce que parler veut dire, Paris, Fayard, 1982.

${ }^{27}$ Aquí discrepo de modo muy crítico con la propuesta del filósofo Richard Rorty quien trata de rescatar el concepto de etnocentrismo y volverlo positivo (es decir, aceptable en términos pragmáticos) para estudiar el modo de trabar relaciones con los otros culturalmente diferentes. En esta postura ambigua, Rorty se esmera en demostrar (sin convencernos del todo) que no existe ningún punto de vista divino, donde se mira objetivamente a todas las opiniones teniéndolas todas a la vista. Cf. Richard Rorty L'ethnocentrisme et la possibilité critique, www. lyber-eclat. net.
} 
UNIVERSIDAD CATÓLICA DE TEMUCO

formas de conocimientos y representaciones están operando en el pensamiento etnocéntrico para relacionarse con el otro, a sabiendas de que dichos conocimientos y representaciones pecan generalmente por su carácter prejuicial e ideológico.

Contestar este conj unto de preguntas ameritaría que dediquemos al tema una investigación doctoral. Nos tocaría indagar esta problemática desde distintos ángulos y conforme a enfoques metodológicos variados y afines. Ni quiero, ni tampoco puedo tener esta pretensión. Ahora bien, la tesis que quiero defender aquí es la siguiente: el etnocentrismo es uno de los varios modos de relación con el otro, aún cuando presupone la aniquilación física (genocidio) o simbólica (etnocidio) de éste. ¡Pero esto no es (lamentablemente) algo nuevo! No obstante, sostengo que el etnocentrismo se fundamenta en lo que Ilamaría un sociocentrismo acorde a cada tipo de sociedad compleja. En otros términos, significa que la construcción del otro en tanto miembro de una cultura exótica estriba en la previa concepción de una alteridad interior conforme al orden social imperante. He aquí la reflexión de G. Simmel sobre el extranjero del interior ${ }^{28}$. Alo largo de la historia social mundial, la figura del otro ha venido a ser multifacética: el Gitano de la España de los Reyes Católicos, el judío en la Alemania de principios del siglo XX, el Indígena en varios países americanos, el vagabundo de las sociedades capitalistas ${ }^{29}$, el desempleado de las sociedades aquejadas por los embates bursátiles, el enfermo mental, constituyen algunos ej emplos del otro interior. Cada sociedad constaría por decirlo así de una experiencia del otro acopiada entre sus propios límites políticos y culturales. Desde luego, dicha experiencia corre varias suertes según una escala ética entre el peor trato y la dudosa y total empatía. Por ende, planteo que es a partir de ella, es decir, con base en ese "capital de alteridades", que se entabla la relación con el otro cercano y/o lejano. A igual que el principio de caridad de que nos habla Donald Davidson ${ }^{30}$ a través de lo que Ilama la "interpretación radical", que estriba en la idea de que todo tipo de traducción (sobre todo en su vertiente radical, la que ha sido desarrollada por el lógico WVO Quine) se inicia forzosamente en casa, el etnocentrimo empieza entre los límites de un círculo familiar determinado incluso en el sentido estricto y empírico de la expresión. En otras palabras, estos límites pueden circunscribirse a una casa, una mansión, un barrio, una ciudad, una región, un estado, una nación o un continente cultural. El otro viene a definirse conforme se desplaza el cursor etnocéntrico: la frontera entre lo propio y lo ajeno fluctúa de acuerdo a los intereses y los beneficios puestos en juego en las relaciones entre grupos sociales y culturales. La reflexión antropológica radical de Quine apunta con insistencia hacia aspectos significativos del etnocentrismo donde el otro se considera sujeto cultural exótico extremo, al tiempo que para Davidson el otro, a partir del cual puede construirse una gigantesca distancia simbólica y "sicológica", bien puede ser el vecino de la esquina o del departamento de enfrente. Para ambos autores, el principio de caridad constituye, mal que bien, una manera de burlar el etnocentrismo que contagia la relación intercultural o la relación social entre ciudadanos diversos de una misma y única nación.

Dicho de otro modo, las representaciones (desde luego desprovistas del principio de caridad arriba mencionado) que de los indios empezaron a construir los españoles prolongan, a la postre, la visión que la sociedad ibérica tenía respecto del moro, del gitano, del judío e inclusive del guanche tinerfeño. La mención de dichas figuras del otro muy a menudo era motivo de menosprecio. Las civilizaciones griega y latina, en cambio, propiciaban un exceso de valoración entre varios cronistas de la conquista quienes no titubearon en comparar las sociedades precortesianas del Valle de México con la civilización helénica. Cabe destacar que en la sociedad española en

\footnotetext{
${ }^{28}$ Véase "Digression sur l'étranger" in L'Ecole de Chicago, textes traduits et présentés par Isaac J oseph et Yves Grafmeyer, paris Aubier, 1990.

${ }^{29}$ Vale la pena recordar aquí el fabuloso trabajo de Alexandre Vexliard, Le clochard, Paris, Desclée de Brouwer, 1957.

${ }^{30}$ Cf. Isabelle Delpla Quine, Davidson, le principe de charité, Paris, Puf, philosophies, 2001, p. 89.
} 
Revista CUHSO volumen $11 \mathrm{n} \div 1$

vísperas del descubrimiento de las Américas, el otro interior en tanto ser vivo despertaba desconfianza, encono y recelo $y$, en tanto difunto, la referencia al otro, ya sea latinizado o helenizado, propiciaba una suerte de bienestar (o beneficio) estético e identificación con un pasado truncado. Finalmente, el etnocentrismo no es sólo una relación con el otro a través del espacio, sino también a través del tiempo. Hoy día, el valor agregado del turismo en México apunta más del lado del indio muerto y de los testimonios arqueológicos que heredan los turistas que visitan estos numerosos sitios, que del lado del indio actual, muy a menudo, pobre, agobiado, marginado y desahuciado por sufrir atropellos diarios de toda índole. En esta tesitura, el caso mexicano es muy interesante puesto que, través de la presencia de varios grupos indígenas, empalman dos concepciones hacia dichas poblaciones: sociocentrismo, es decir, relaciones clasistas, y etnocentrismo, a saber, relaciones interculturales.

\section{En este acápite, la recién desaparición} del Instituto National Indigenista (INI), sustituido por la Comisión Nacional de Desarrollo de los Pueblos Indios (CDI), no es un hecho irrelevante con respecto al tema que les presento hoy. En efecto, si bien el INI pecó por una suerte de etnocentrismo asistencialista para con los grupos indígenas de la República y fracasó en parte por exceso de burocracia, duplicación de las acciones emprendidas y falta de coordinación en los programas implementados por las distintas secretarías partícipesdel indigenismo de Estado, nunca pecó por maltusianismo (utilitarismo). La Comisión da la pauta para otra suerte de etnocentrismo más radical: el indigenismo pasa entonces de ser revolucionario a ser empresarial, donde la realidad étnica se mide con criterios de rentabilidad conforme a las tendencias del mercado y a los altibajos bursátiles. De hoy en adelante, lo indígena será sobre todo una mercancía de consumo o exportación: bosque, tierra, agua, músicas tradicionales, artesanías, cenotes sagrados, mano de obra barata, etc. Con este giro político parece desvanecerse el concepto de servicio público y, mal que bien, la atención a poblaciones desprotegidas, como son los grupos indígenas mexicanos. Mejorar el funcionamiento del INI nunca ha significado hacerlo desaparecer y sobre todo no se sabe bien a bien de qué manera esta reforma va a beneficiar a los grupos étnicos del país. Finalmente, con la creación de la Comisión se destierra el último y ambicioso proyecto del Instituo de alentar la autonomía de los grupos indígenas y transformar, a la postre, el INI en instrumento para alcanzar esta meta.

Es preciso recalcar, además, que el uso de la palabra "desarrollo" participa de la gramática del etnocentrismo tal como los términos "proyecto", "evolucionismo", "progreso"31, "civilización", "modernidad", "tecnología", "metrópoli" e incluso "historia". Este vocabulario, cuyas reglas de uso remiten al universo político así como científico, conforma un juego de lenguaje en el sentido de L. Wittgenstein ${ }^{32}$. Es muy difícil ser político hoy en día y obviar en sus discursos dicho acopio de palabras ideologizadas. En efecto, como hubiese dicho Edmond Cros, el uso de la palabra " desarrollo " supone un no consciente, es decir todo aquello que está detrás de este concepto. Son muchas las preguntas que podríamos formular al respecto:

\footnotetext{
31 J ohann Nestroy (1801-1862), actor austriaco, comentaba respecto del progreso : “iSiempre parece más grande de lo que es en realidad! Cf. L. Wittgenstein in Remarques sur le rameau d'or de Frazer, suivi J acques Bouveresse, L'Animal cérémoniel, Wittgenstein et I'anthropologie, Lausanne; I'Âge de I'Homme, le bruit du temps, 1982, p. 76.

32 Cf. Les investigations philosophiques, Paris, Gallimard, 1962.

33 Esto es de acuerdo a las enseñanzas de la filosofia del segundo Wittgenstein ¿Cómo hemos venido a aprender el uso cultural e ideológico del término "desarrrollo", en la escuela, en los medios masivos, en el discurso político en general y en particular como es el caso de los partidos, de las ONG, de los sindicatos y los grupos altermundialistas, en las revistas especializadas de ciencias humanas, en la filosofía política, en las relaciones cotidianas con sus coetáneos, etc.? Frente a ello, considero que existen tres posturas que describen cada una dos relaciones hacia el etnocentrismo: 1) una postura neoliberal que considera que el "todopoderoso mercado" logra regular las relaciones entre las culturas y luego entonces el problema del desarrollo de los países periféricos se dirime mediante la aplicación de las reglas de la demanda y de la oferta; 2) una postura reformista, que considera que se tiene que mejorar y adecuar las proposiciones del desarrollo apegándolas a intereses y situaciones locales considerando entonces que, de un modo u otro, se puede rescatar el concepto de desarrollo (el problema es que, muy a menudo, esta última postura viene a alimentar, matizar, legitimar y finalmente reforzar la primera postura neoliberal, a través de formas eclécticas de desarrollo tales como son el eco-desarrollo, el etno-desarrollo, el desarrollo local o al manejar proyectos de desarrollo auto-sostenibles con grupos desamparados y excluidos y en tercer lugar, una postura de rechazo radical y utópico a toda forma de desarrollo, considerando que el problema se origina en el pensamiento liberal el cual convierte la idea de progreso, y luego entonces el concepto de desarrollo, en mera satisfacción (e imposible objetivo) del deseo individual y social instituido en consumo a gran escala. Es obvio que hablar de desarrollo no es sino tocar el tema del etnocentrismo. En esta última postura, encontramos las tesis del filósofo norteamericano Christopher Lasch.
} 
¿Qué se entiende por la palabra "desarrollo" ${ }^{33}$ ? ¿Quiénes son los beneficiados reales del "desarrollo" ? ¿De qué sirve desarrollar la economía de sociedades tradicionales como son las comunidades indígenas del país? ¿Qué es lo que se quiere desarrollar ? y finalmente ¿Por qué es necesario "el desarrollo"?

El concepto de desarrollo es, en sumo grado, un indicador del pensamiento etnocéntrico. La gramática de esta forma de pensar gira en torno a una concepción del tiempo que termina por ordenar los espacios físicos en que radican sociedades nacionales y grupos sociales. Esta gramática devela una superioridad técnica, material, política, económica, mas no intelectual. Su lema sería : la verdad es (siempre) la del vencedor. Con esta superioridad, cuya forma social es un tipo de certidumbre de orden natural, se desprenden varias creencias que orientan la acción individual y/o colectiva del etnocentrismo. Salvo casos extremos, el etnocentrista desde luego no se reconoce como tal. Para bien y para mal, considera su relación con el otro natural, es decir, como si ésta dependiera de un orden universal en el cual él no influye. Como hubiese dicho Pierre Bourdieu, ser etnocentrista consiste en manifestar un habitus (disposición para pensar y actuar). Cuando políticos mexicanos y asesores presidenciales proponen reformar el INI y sustituirlo por la CDI, no tienen, desde luego, como meta acabar con las sociedades tradicionales del país. Sin embargo, su metodología difícilmente pasa por alto el fondo de representaciones sociales que participan de la construcción histórica de la figura del indio mexicano y esto es así pese a los acontecimientos de Chiapas, que apuntan hacia un despertar de los pueblos indios tanto en México como en otros países americanos ${ }^{34}$.

La CDI es el reflejo tanto de la historia de México, en cuyo decurso el indio ha tenido varios papeles (el salvaje, el enemigo, el feligrés, el chinaco, el peón, el campesino, el símbolo de la nación, el migrante a la ciudad, el elector, entre otros), como de los ajustes económicos neoliberales actuales a nivel internacional donde todas las políticas sociales son consideradas sospechas por tener un costo financiero y por reforzar el papel del Estado. Bajo este enfoque, el etnocentrismo de Ia CD combina dos visiones: una es lejana, el indio es un menesteroso entre muchos millones, y otra es cercana, el indio sigue cuestionando la unidad nacional del país no tanto por arremeter contra la misma sino más bien por no tener un lugar claramente definido.

Quisiera concluir esta ponencia con unas palabras edificantes (eufemismo) de un otrora desconocido general mexicano, el señor Miguel Ángel Godínez, que actúo en el frente chiapaneco, escasos días después del levantamiento en armas del EZLN, el uno de enero de 1994. Sus comentarios pocos amenos son un elemento más vertido al expediente del etnocentrismo que se manifiesta tanto en México como en el resto del mundo:

“Los Indígenas siguen viviendo como hace tres ó cuatro siglos ... Siguen usando leña, comen maíz; no hablan español; se visten de la misma manera y andan descalzos. No entendemos bien lo que quieren. Cuando uno platica con ellos, creo que hasta en su propio medio se sienten felices como son." 35

\section{BIBLIOGRAFÍA}

BLONDEL, MAURICE. L'Action, Paris, Puf, coll. Quadrige, 1993 (1 èrédition en 1893).

BOURDIEU, PIERRE. Ce que parler veut dire, Paris, Fayard, 1982.

-.--- Esquisse d'une théorie de la pratique, Paris, Minuit, 1980.

\footnotetext{
${ }^{34}$ Sin embargo, hay que matizar este entusiasmo militante y/ o simpatía juvenil hacia los grupos indios americanos, puesto que cada diez años aproximadamente se pregona un nuevo despertar de dichos grupos cuya legítima lucha habría de desembocar en un supuesto cambio político rotundo. De hecho, no se sabe a ciencia cierta si se trata de una realidad fehaciente o bien de una prueba más del mesianismo que acompaña los movimientos sociales indígenas a lo largo de la historia y a lo ancho del continente americano.

35 Cf. General Miguel Angel Godínez, comandante de la VII región militar de Chiapas, El Financiero, 22 de enero de 1994. Hoy día, es diputado federal por el PRI.
} 


\section{Revista CUHSO volumen $11 \mathrm{n} \div 1$}

----- Le sens pratique, Paris, Minuit, 1980.

DELPLA, ISABELLE. Quine, Davidson, le principe de charité, Paris, Puf, philosophies, 2001.

DUBOIS, J. ET ALII, Dictionnaire étymologique et historique du français, Paris, Larousse, 1997.

GEERTZ, CLIFFORD. Los usos de la diversidad, Barcelona, Paidós, 1999 y La interpretación de Ias culturas, Barcelona, Gedisa, 1989.

----- Ici et là-bas, l'anthropologue comme auteur, Paris, Métailié, 1996

JAKOBSON, ROMAN. Huit questions de poétique, Paris, Seuil, 1977.

LEVI-STRAUSS, CLAUDE. Le regard éloigné, Paris, Plon, 1983.

Race et histoire, Paris, Éditions Gonthier, Unesco, 1961.

MERTON, ROBERT KING. Éléments de théories et de méthode sociologique, Paris, Armand Colin, 1997.

PUTNAM, HILARY. Raison, vérité et histoire, Paris, Éditions de Minuit, 1984.

RORTY, RICHARD. L'ethnocentrisme et la possibilité critique, www. lyber-eclat. net.

SARTRE, J EAN-PAUL. Réflexions sur la question juive, Paris, Gallimard, collection Folio/ Essais, 1990.

SCHAFFHAUSER, PHILIPPE. «Indiens et identité au Mexique: l'exemple de la Meseta Purépecha», Doctorado en sociología por la Universidad de Perpignan, 1997.

SIMMEL, GEORG. "Digression sur l'étranger" in L'Ecole de Chicago, traduits et présentés par Isaac J oseph et Yves Grafmeyer, Paris, Aubier, 1990.

SUMNER, WILLIAM GRAHAM. Folkways : a study of the sociological importance of usages, manners, customs, mores and morals, 1906.
VEXLIARD, ALEXANDRE. Le clochard, Paris, Desclée de Brouwer, 1957.

WITTGENSTEIN, LUDWIG. Les Investigations philosophiques, Paris, Gallimard, 1962.

Remarques sur le rameau d'or de Frazer, suivi J acques Bouveresse, L'Animal cérémoniel, Wittgenstein et I'anthropologie, Lausanne, I'Âge de l'Homme, le bruit du temps, 1982. 